This is an electronic reprint of the original article. This reprint may differ from the original in pagination and typographic detail.

Author(s): Siitari, Heli; Alatalo, Rauno Veli; Halme, Panu; Buchanan, KL; Kilpimaa, Janne

Title: $\quad$ Color Signals in the Black Grouse (Tetrao tetrix): Signal Properties and Their Condition Dependency

Year: $\quad 2007$

Version:

Please cite the original version:

Siitari, H., Alatalo, R. V., Halme, P., Buchanan, K., \& Kilpimaa, J. (2007). Color Signals in the Black Grouse (Tetrao tetrix): Signal Properties and Their Condition Dependency. In American Naturalist (169, pp. S81-S92). American Naturalist. https://doi.org/10.1086/510140

All material supplied via JYX is protected by copyright and other intellectual property rights, and duplication or sale of all or part of any of the repository collections is not permitted, except that material may be duplicated by you for your research use or educational purposes in electronic or print form. You must obtain permission for any other use. Electronic or print copies may not be offered, whether for sale or otherwise to anyone who is not an authorised user. 


\title{
Color Signals in the Black Grouse (Tetrao tetrix): Signal Properties and Their Condition Dependency
}

\author{
Heli Siitari, ${ }^{1, *}$ Rauno V. Alatalo, ${ }^{1, \dagger}$ Panu Halme, ${ }^{1, \ddagger}$ Katherine L. Buchanan, ${ }^{2, \S}$ and Janne Kilpimaa ${ }^{3, \|}$
}

1. Department of Biological and Environmental Science, University of Jyväskylä, P.O. Box 35, FI-40014 Jyväskylä, Finland; 2. Cardiff School of Biosciences, Main Building, Museum Avenue, Cardiff CF10 3TL, United Kingdom;

3. Department of Biology, University of Turku, FI-20014 Turku, Finland

ABSTRACT: Recent progress in techniques of quantifying betweenindividual differences of color-based ornaments has revealed undiscovered possibilities for research in sexual selection. We present how the color spectra data can be comprehensively used for studying the importance of sexual ornaments in the black grouse and how these ornaments are related to a male condition. For this, we used both correlative field and experimental data. Field data indicated that older males had more chromatic coloration than yearlings. Blue chroma of males was correlated with male mating success. We experimentally manipulated yearling birds with testosterone implants and found that testosterone-implanted males had impaired expression of several sexual ornaments: 10 months after the implantation, both structuralbased blue and carotenoid-based red eye comb coloration were diminished, as well as lyre (tail) length. However, the manipulation did not affect vital traits under natural selection (wing length or body mass). Our data indicate that structural color is an important trait in sexual selection in this lekking species. Importantly, the data also indicate that male sexual ornaments are more susceptible to environmental conditions than the other male traits, thus showing their heightened condition dependency compared with the other traits mediating the honesty of signaling.

Keywords: carotenoids, color spectrum analysis, sexual selection, structural coloration, testosterone.

The handicap principle of sexual selection predicts that sexual selection promotes the evolution of honest sexual

\footnotetext{
* Corresponding author; e-mail: hesasi@bytl.jyu.fi.

† E-mail: alatalo@bytl.jyu.fi.

‡ E-mail: pahalme@cc.jyu.fi.

§ E-mail: kate.buchanan@cardiff.ac.uk.

"| E-mail: kjkilpim@cc.jyu.fi.
}

Am. Nat. 2007. Vol. 169, pp. S81-S92. (c) 2007 by The University of Chicago. 0003-0147/2007/1690S1-40689\$15.00. All rights reserved. signals (Andersson 1994) and that these signals express heightened condition dependency reflecting male genetic quality (Pomiankowski 1987; Grafen 1990; Iwasa and Pomiankowski 1994). Males of high genetic quality should then express greater sexual trait size or display, whereas poor males are unable to resist the associated viability costs (reviewed in Cotton et al. 2004). Male quality may also vary according to environmental conditions, directly affecting some reproductive abilities, such as fertility or parenting (Iwasa and Pomiankowski 1999). Thus, sexual traits may similarly reflect a male's genetic resistance to environmental stress.

A wide range of plumage traits are often affected by avian sexual selection (Hamilton and Zuk 1982; Andersson 1994). Recent advances in our knowledge of avian vision and techniques in measuring color variation per se (see, e.g., Bennett et al. 1994; Cuthill et al. 1999, 2000; Sheldon et al. 1999; Foerster et al. 2003; Osorio and Vorobyev 2005) have opened new challenges for associated research. If plumage coloration indicates male phenotypic condition, females, when choosing brightly colored males, may benefit in terms of direct benefits, for example, better breeding sites (Keyser and Hill 1999), increased feeding rates of incubating females (Hill 1991), and the young (e.g., Hill 1991; Palokangas et al. 1994; Keyser and Hill 2000). In addition to the possibility of direct benefits, a number of studies have provided both theoretical (e.g., Andersson 1986) and empirical evidence that females may obtain indirect genetic benefits by choosing males with elaborate plumage traits (e.g., Petrie 1994; Hasselquist et al. 1996; Sheldon et al. 1997, 1999; Møller and Alatalo 1999; Foerster et al. 2003).

Avian colors are due to either pigmentation (carotenoid and melanin pigments) or feather structures (structural colors). Structural colors are produced by feather structures rather than by pigmentation. In addition to birds, they are common in butterflies, fish, and insects (Fox 1976). Structural colors include colors of ultraviolet, blue, some greens, and iridescent plumage. Most of the studies on avian plumage colors have concentrated on pigment colors. Their signaling function and condition dependence 
have been intensively investigated and are more thoroughly understood (e.g., Senar 1998; Hill 1999; Andersson et al. 2002; Pryke et al. 2002; Alonso-Alvarez et al. 2004) than those of structural colors. It is clear that structural colors have importance in mate choice and pairings in many species (Bennett et al. 1996, 1997; Andersson et al. 1998; Hunt et al. 1998, 1999; Pearn et al. 2001; Siitari et al. 2002; but see Ballentine and Hill 2003). Recent studies additionally indicate that structural-based sexual ornament (crown coloration) in the blue tit (Parus caeruleus) predicts male survival (Sheldon et al. 1999; Griffith et al. 2003). In addition, this ornament is positively related to male genetic diversity (as measured by heterozygosity; Foerster et al. 2003) and is inherited from parents to offspring (Johnsen et al. 2003). The condition dependence is much less understood. There is, however, growing evidence that these colors are, at some stage, condition dependent (Keyser and Hill 1999, 2000; Siitari and Huhta 2002; Johnsen et al. 2003). For example, it is known that nutritional stress has negative effects on structural colors in brown-headed cowbirds (Molothrus ater; McGraw et al. 2002). Furthermore, a study on the color variation in eastern bluebirds (Sialia sialis; Shawkey et al. 2003) supports the idea that the condition dependence of structural colors could be mediated via the feather nanostructure, mainly through variation in the number and size of keratin rods (see also Fitzpatrick 1998; Andersson 1999).

Black grouse is a lekking species with strong sexual selection (Alatalo et al. 1991; Höglund and Alatalo 1995). Males have several sexual ornaments, which are expressed in relation to male condition, reflecting, for example, male viability, fighting ability, and parasite resistance (Höglund et al. 1992). Male testosterone levels increase during the mating time, increasing male mating effort (Alatalo et al. 1996b). Male testosterone levels are positively correlated with eye comb size (Rintamäki et al. 2000), and furthermore, male testosterone levels are positively related to male mating success (Alatalo et al. 1996b). Molt takes place after the mating season in June-late August.

In this study, we investigated how spectrophotometric measurements of breast feathers and eye comb are related to male age and condition. In addition, we quantified the importance of color ornaments in predicting male mating success in this species. Finally, we tested experimentally how increased testosterone levels affect both structural and carotenoid-based coloration and male mating success in the following year and survival in the consecutive years. Furthermore, we investigated whether the testosterone manipulation differentially affected sexually and naturally selected fitness-related traits (investment in ornaments vs. survival, body mass, and flight ability). This is because stress and sex hormones can interact with both biotransformation (Prough et al. 1996) and immune system (e.g.,
Folstad and Karter 1992; Råberg et al. 1998; Kilpimaa et al. 2004), possibly affecting both the production of free radicals and the expression of secondary sexual traits. Our study focused on structural colors, and mechanisms that control the development of structural color-based ornaments are poorly understood.

\section{Methods}

Field Work

This study was conducted on leks in central Finland, one of which is a natural bog (Petäjävesi-Teerijärvensuo, 20012002) and three others that are currently used for peat exploitation (Petäjävesi-Valkeissuo, Multia-Kummunsuo, Keuruu-Lehtosuo, all in 2002). Additionally, the survival of the males was monitored yearly until 2005. On these sites, black grouse males gather for lekking (main lekking time: March-early June; autumn lek: late August-early November) every year. Winter feeding sites (with oat seeds) were established for these sites to enable capturing outside the main lekking season. The total winter flock size varied from 55 to 100 individuals, of which about $60 \%$ were males. In every year, we captured both males and females starting in January and continuing until the end of March-mid-April. The individuals were captured with walk-in traps for one to five times per trapping season (for the methods, see, e.g., Alatalo et al. 1996b).

Each captured individual was marked with aluminum and color rings for future identification. We measured their wing length (accuracy $1.0 \mathrm{~mm}$ ), lyre (tail) length (accuracy $1.0 \mathrm{~mm}$ ), and body mass (accuracy $10 \mathrm{~g}$ ). The color of the red eye comb was measured with a spectrophotometer (maximally once every 3 weeks; here, only the results relevant to the testosterone implantation experiment are shown). A feather sample of five to 10 feathers was taken from the breast area of males in the first capture in January-February of the given year. This was preserved in a paper envelope for spectroradiometry later in the laboratory (for methods, see below). We also recorded male eye comb size with digital video cameras with a known standard (squared millimeter paper) every time the eye comb color was measured.

\section{Breast Feather Data}

In the laboratory, we measured the color spectrum of blue breast feather samples using a spectroradiometer (GS 3100, EG \& G Gamma Scientific, San Diego, CA). The spectra were recorded three times per sample over the range from 320 to $700 \mathrm{~nm}$ in steps of $5 \mathrm{~nm}$ and were calculated relative to a $99 \%$ white reflectance standard (LabSphere). The location for measurement within each sample was randomly 
chosen within the bluish area on the tip of the feathers. All spectroradiometry was conducted blind to the feather origin. The feathers were placed on a black velvet background where the reflectance was low in all wavelengths to eliminate any possible reflection from the background. The sample was illuminated at $55^{\circ}$ to the measuring surface by an EG \& G RS-22 UV xenon fiber-optic light source. The illumination was always from the proximal end of the feathers. Reflected light was collected with the fiber-optic probe at $90^{\circ}$ to the sample ( $35^{\circ}$ to illumination) connected to an adjustable mounting stand (191C-02, EG \& G Gamma Scientific) at the fixed distance of $17 \mathrm{~mm}$. The spot area measured was $1 \mathrm{~mm} \times 1.5 \mathrm{~mm}$, and the measurements were carried out in a dark room to avoid any confounding effects of background illumination. The typical reflectance spectra of blue breast feathers are represented in figure $1 a$. The reflectance levels are low (up to $6.5 \%$ ), but the spectra show a clear peak in the near-UVblue area. The feathers were dark blue also in our own eyes, and their hue did not change if the viewing angle was changed.

All the diurnal bird species investigated so far have the potential to detect near-UV light $(320-400 \mathrm{~nm}$; Cuthill et al. 2000). The lens of the bird eye is UV transparent, which enables them to see in the UV light. Moreover, the UV/ violet cone sensitivity peak of, for example, many passerine species is within the near-UV area (in many cases, close to $370 \mathrm{~nm}$ ). However, the shortwave cone sensitivity peak of Galliformes species is in the violet area, at $420 \mathrm{~nm}$ (see Cuthill et al. 2000). This suggests that the main area for signaling in galliform species is located within the human visible range $(>400 \mathrm{~nm})$. Because of this and the fact that the reflectance peak of breast feathers of the black grouse was within the UV-blue wavelengths, we started to analyze our breast feather data by calculating both $\mathrm{UV}\left(\mathrm{R}_{320-400 \mathrm{~nm}} /\right.$ $\left.\mathrm{R}_{320-700 \mathrm{~nm}}\right)$ and blue $\left(\mathrm{R}_{405-480 \mathrm{~nm}} / \mathrm{R}_{320-700 \mathrm{~nm}}\right)$ chroma indexes from the color reflectance spectra. The total reflectance (often called total brightness), $\mathrm{R}_{320-700 \mathrm{~nm}}$, was also included in the statistical analysis. Each color index (UV chroma, blue chroma, total reflectance) was calculated separately for the three spectra measured for each individual, and after this, the mean of the three separate values for each index was calculated and used in the analyses.

To investigate comprehensively the breast feather color reflectance curves, we additionally conducted a principal component analysis (PCA) for the color spectra (Bennett et al. 1997). Each breast feather spectrum consists of 77 data points (the reflectance from 320 to $700 \mathrm{~nm}$ at $5-\mathrm{nm}$ intervals). Principal component analysis summarizes a large number of correlated variables into a few orthogonal variables called principal components (for a detailed description of how PCA can be used for color spectra analysis, see Endler 1990; Cuthill et al. 1999). The major var-
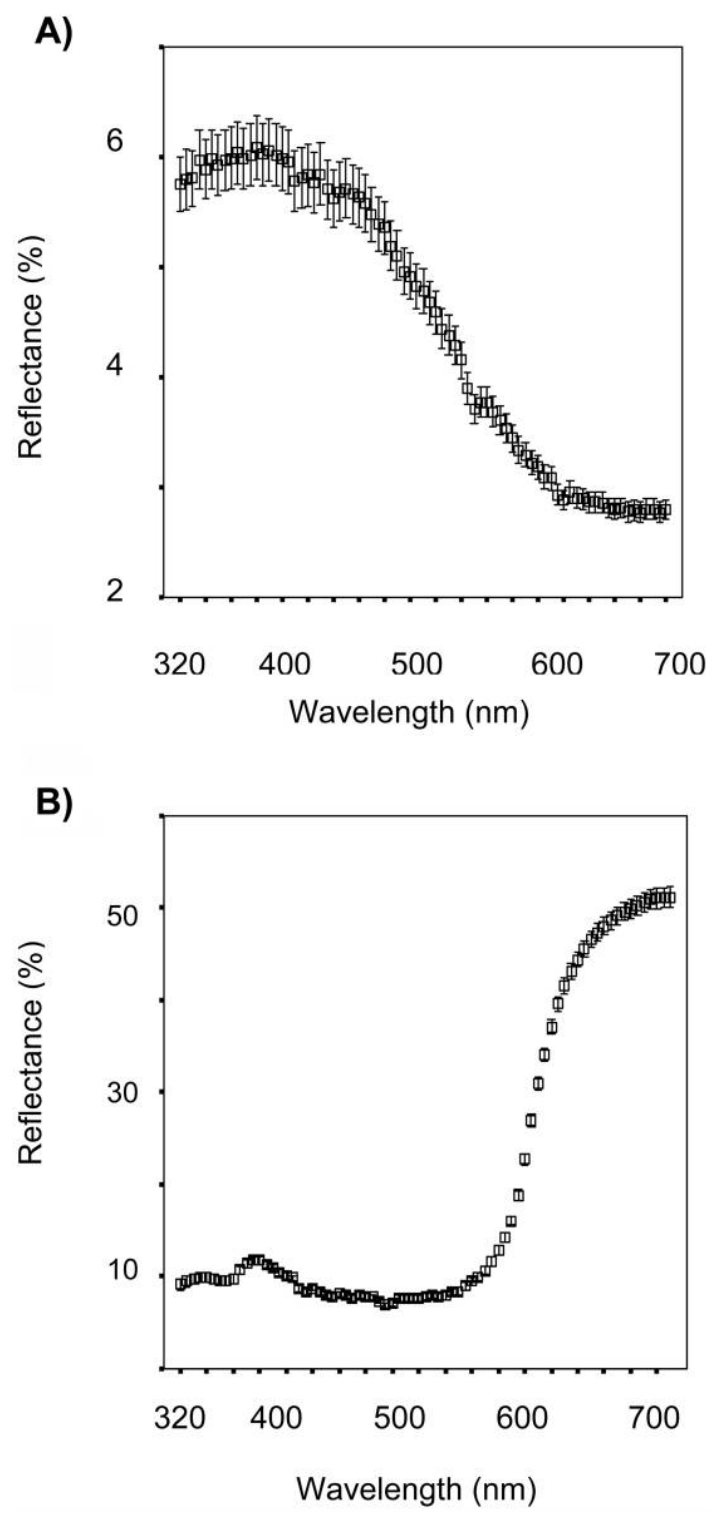

Figure 1: Typical mean reflectance spectra $( \pm 1 \mathrm{SE})$ of male blue breast feathers $(A)$ and red eye comb $(B)$ measured with optical spectrometry.

iation between color spectra is based on differences in brightness (Endler 1990; Endler and Théry 1996; Cuthill et al. 1999), whereas in this study, our aim was to characterize the chroma (spectral purity or saturation) differences between individuals. Thus, each spectrum was first standardized by dividing each data point by its own total reflectance $\left(\mathrm{R}_{320-700}\right)$. After this, we further reduced data points to the means of $20-\mathrm{nm}$ bandwidths between 320 and $700 \mathrm{~nm}$, ending up with 19 data points for each color reflectance curve that were used for PCA. This was done to reduce the number of data points for the analyses and 
to make the figures concerning the PCA results clearer. A PCA was conducted for this data set, combining data from years 2001 and 2002 (years do not differ, $P>.1$ for all color indexes). Data for this is mainly from 2002; we had only one lek in 2001 and no overlapping individuals between 2001 and 2002.

\section{Testosterone Implantation Experiment}

In March 2002, we conducted an experiment in three bogs (Teerijärvensuo, Kummunsuo, Valkeissuo), where we manipulated testosterone levels of yearling black grouse males. For this, we captured 38 young males (implantation capture; March 6-18, 2002), of which 19 males were implanted with testosterone implants and 19 males were unmanipulated controls (for implantation details, see information below). During each capture attempt, the same number of young males was assigned for implanted and control groups. Some of the males were captured earlier in the season in 2002, but we did not start the implantation until March 2002. This was because of the time-limited effects of the implant (about 2 months, according to Zuk et al. [1995], for implants similar to those used here), which we wanted to be the most effective just before and during the mating time in the end of April-early May. We implanted the experimental males with $60 \mathrm{mg}$ of crystalline testosterone (Sigma T1500) in silastic tubes (Dow Corning, Midland, MI; length $42 \mathrm{~mm}$, diameter $3.14 \mathrm{~mm}$; both ends of implants sealed with a medical adhesive [medical grade adhesive 40086, Sikema AB, Stockholm]) by inserting two implants (30 mg of testosterone each) under the skin in the male breast muscle (male body mass 1,100-1,270 g) and sealing the insertion wound with the same medical adhesive as above. The treatment and the amount of testosterone were adjusted from Zuk et al. (1995; red jungle fowl Gallus gallus) according to black grouse testosterone levels (Alatalo et al. 1996b). To ensure that the manipulation would not be unnaturally strong, we reduced our implants to two-thirds of those used by Zuk et al. (1995) for similar-sized jungle fowl.

The experimental males were recaptured from 14 to 33 days (mean $=23.0, \mathrm{SD}=6.4$ ) after the implantation capture, and a blood sample was drawn $(1.5 \mathrm{~mL}$ from a brachial vein, centrifuged and the plasma stored at $-20^{\circ} \mathrm{C}$ until testosterone analyses; see below for details), the eye comb was measured (size, color), and body mass measurements were again taken. A subsample of birds was caught again in their lekking arenas from 41 to 59 days (mean $=51.9, \mathrm{SD}=5.2$ ) after the implantation capture, and the same measurements were again conducted.

During the main lekking time in 2002 (45-60 days after the implantation capture) in late April-early May in both years, mating success and display behavior of implanted and control males were observed from hides throughout the morning (details, e.g., in Alatalo et al. 1992, 1996b). The leks were monitored over the whole period of matings, which lasted 7-10 days (also for years 2001-2002). Male display behavior was recorded each morning at 5-min intervals when females were absent from the lekking arena. The positions of all the males were plotted on a specific map at an accuracy of $1 \mathrm{~m}$. The center of each lek was defined as the median for the horizontal and vertical axes for all the male observations during the mating season. The median of the observations of a particular male was defined and compared with the center of the lek to reflect the centrality of the certain male. The implants were removed when the males were recaptured in 2003 (all recaptures between mid-January and early February in 2003, when the feather samples were also collected). The survival rate was estimated from the recapturing and lekking data from 2002 to 2005 (Alatalo et al. 1991; Höglund et al. 1999).

\section{Eye Comb Measurements in 2002 and 2003}

We assessed the coloration and size of male red eye combs for the captured males. For this, each eye comb was measured with an Ocean Optics USB2000 spectrophotometer over the range from 320 to $700 \mathrm{~nm}$ in the field. Briefly, fiber-optic cable (P400-2-UV/VIS) surrounded by six illuminating fibers (PX-2 high-power xenon light source), with a matte black plastic sheath enclosing the end of the probe, was placed perpendicularly against the eye comb. The distance between measuring probe and the eye comb was approximately $12 \mathrm{~mm}$. The strobe illuminated an area of the eye comb approximately $1.5 \mathrm{~mm}$ in diameter. Each eye comb was measured six times per side in 2002, reduced to four times per side in 2003. We changed the measuring spot within an eye comb between every measurement and varied the measuring eye comb between the right and left after every two measurements. Referencing with a $99 \%$ white standard (LabSphere) was conducted before the first measurement and repeated every time after four measurements (two per side). The repeatability for the eight measurements in one measuring time (calculated from 2003 data) was relatively high $(R=0.82$, all males included; $F=36.23$, df $=247,1,725, P<.0001)$, and mean values were used for each male. For the typical reflectance spectra of red eye combs, see figure $1 b$. Eye comb size $\left(\mathrm{cm}^{2}\right)$ was calculated as the sum of right and left eye comb areas, calculated from digital video shots with known standard using ImagePro software. To calculate the hue of the red eye comb (redness), we used the spectral location, which is the frequency $(\mathrm{nm})$ where the reflectance is $50 \%$ of the maximum (modified from Pryke and Andersson 2003). 


\section{Testosterone Analysis}

Circulating testosterone concentrations were estimated using direct radioimmunoassay of stored plasma samples. Samples were analyzed in one assay, run in November 2003. Testosterone concentrations were measured using antitestosterone antiserum (code 8680-6004, Biogenesis, Oxford) and $\left[{ }^{125} \mathrm{I}\right]$-testosterone label (code 07-189126, ICN, London; Parkinson and Follett 1995). Although there is some cross-reaction of the antiserum with other androgens in the plasma, the cross-reactivity is low, and therefore this assay presents a reliable surrogate measure of absolute testosterone levels. It was confirmed that black grouse plasma samples diluted parallel with the standard curve. The assay was run with $50 \%$ binding at $7.0 \mathrm{pg}^{\text {tube }} \mathrm{e}^{-1}$ and a detection limit of $0.02 \mathrm{ng} \mathrm{mL} \mathrm{mL}^{-1}$ for the duplicate $10-\mu \mathrm{L}$ plasma volumes that were run in the assay.

\section{Data Analyses}

Mating success in lekking species is often highly skewed among males, as it is in our study population (Alatalo et al. 1992). Thus, we apply nonparametric statistics for mating success analysis (Spearman's rank correlation). In addition, matings occur almost solely between females and old males, and thus mating success data are included only for the older males. Male mating success (=number of copulations per mating season) on the lek was observed on all the leks in each year throughout the main mating season, and it was used as a direct measure of male fitness. Paternity of the whole brood is obtained through one copulation (Alatalo et al. 1996a). Since not all the males were recaptured in the testosterone experiment, we use group means of the implanted and control males when comparing morphology, behavior, and plumage traits of implanted and control males. Data for eye comb redness and eye comb size was corrected with date (2003 data; in 2002, all the values were measured in March) using linear regression against date (the predicted value for March 20 presented for eye comb redness; April 1 for eye comb size), since redness decreases and size increases linearly with the date (data not shown). Survival of implanted and control males from 2002 to 2005 was compared using Gehan statistics at life table options in SPSS programs. Statistical analysis was conducted with SPSS for Windows, versions 11.5-12.0. All the probability values are two tailed, and significance was set at $P<.05$.

\section{Results}

Color Analysis: Male Mating Success and Age Differences

In the PCA for breast feather data where the reflectance was standardized with total brightness, two main principal components (PCs) were extracted. The first principal component (PC1) explained $75.36 \%$ and the second (PC2) explained $20.94 \%$ of total variance (altogether $96.30 \%$ of variance). The PC1 and PC2 correlation coefficients over the wavelengths are presented in figure 2. The PC1 has high positive correlation coefficient values in short wavelengths (UV-blue area) and high negative correlation coefficient values in long wavelengths. It thus represents variation in relative amount of short- to long-wavelength reflectance. The PC2 instead has the highest positive correlation coefficient values in midwavelengths (green area; $\sim 480-515 \mathrm{~nm}$ ) but explaining much less of the total variance.

In table 1 , the correlations between the separate color indexes, PCs, and male mating success are presented (separately for young and older males). Blue chroma and UV chroma are positively correlated with each other in both age classes. Blue chroma is strongly positively correlated with total reflectance in both yearling and older males (table 1). Both blue chroma and UV chroma are positively correlated with PC1 in both age classes. However, only blue chroma is significantly positively correlated with male mating success (table 1, older males only).

Yearling and older ( $>1$ year) individuals (data from 2001 and 2002) differed in all their color indexes except PC2, with yearlings having smaller values than the older ones (table 2; yearlings: $N_{2001}=13, N_{2002}=45$; older: $N_{2001}=$ $22, N_{2002}=52$ ). Eye comb redness and size was measured

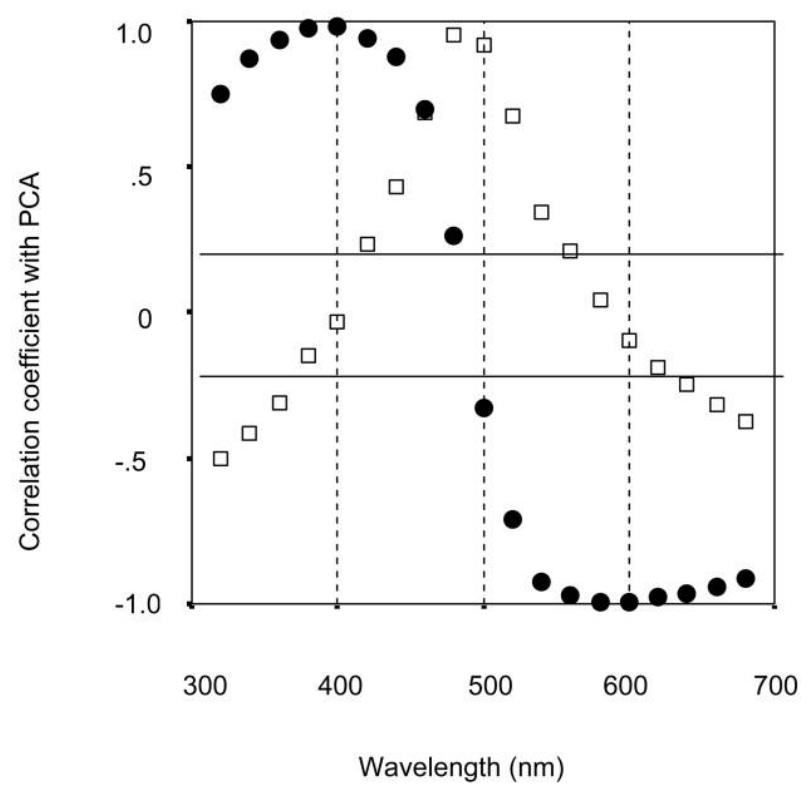

Figure 2: Correlations $(r)$ of the principal components 1 (circles) and 2 (squares) with wavelengths in old ( $>1$ year) black grouse males $(N=$ 71). Horizontal lines indicate the critical values for $P<.05$. 
Table 1: Spearman's correlation coefficients between separate color indexes and principal components (PCs) for yearling and older ( $>1$ year) males

\begin{tabular}{|c|c|c|c|c|c|c|c|c|c|c|}
\hline & \multicolumn{2}{|c|}{ Blue chroma } & \multicolumn{2}{|c|}{ UV chroma } & \multicolumn{2}{|c|}{ Total reflectance } & \multicolumn{2}{|c|}{ PC1 } & \multicolumn{2}{|c|}{ PC2 } \\
\hline & $r$ & $N$ & $r$ & $N$ & $r$ & $N$ & $r$ & $N$ & $r$ & $N$ \\
\hline Blue chroma & $\ldots$ & $\ldots$ & $.784^{\star * *}$ & 58 & $.781^{\star * *}$ & 58 & $.943^{* * *}$ & 58 & $.393^{* *}$ & 58 \\
\hline UV chroma & $.402^{\star \star}$ & 74 & $\ldots$ & $\cdots$ & $.525^{\star \star \star}$ & 58 & $.924^{\star * *}$ & 58 & -.125 & 58 \\
\hline Total reflectance & $.762^{\star \star \star}$ & 74 & $.250^{\star}$ & 74 & $\ldots$ & $\ldots$ & $.697^{\star \star \star}$ & 58 & $.494^{\star *}$ & 58 \\
\hline $\mathrm{PC} 1$ & $.807^{\star * \star}$ & 74 & $.837^{\star * *}$ & 74 & $.620^{* * *}$ & 74 & $\ldots$ & $\ldots$ & .171 & 58 \\
\hline PC2 & $.378^{\star \star}$ & 74 & $-.532^{\star \star \star}$ & 74 & $.530^{\star \star}$ & 74 & -.087 & 74 & $\ldots$ & $\ldots$ \\
\hline Copulations & $.371^{\star \star}$ & 49 & .103 & 49 & .200 & 49 & .277 & 49 & .069 & 49 \\
\hline
\end{tabular}

Note: Data for yearlings are presented in upper diagonal, and data for older males are in bold in lower diagonal. $N=$ sample size.

$* P<.05$.

** $P<.01$.

$* * * P<.001$.

only from March 2002 onward, and both differed between male age classes (table 2). Lyre length (measured in 2001 and 2002) differed between young and old males (yearlings: $N_{2001}=21, N_{2002}=71$, older $N_{2001}=27, N_{2002}=76$ ).

To find out which specific wavelengths are associated with male mating success, we plotted the correlation coefficients between mating success and the reflectance of males in each 20-nm interval of the spectrum (fig. 3). In other words, we want to describe in which wave bands the variation in reflectance between males explains their mating success. Figure 4 indicates that wavelengths 380 $435 \mathrm{~nm}$ are the ones that are the most associated with male mating success, a wave band area where the short wavelength sensitivity peak exists in galliform species (Cuthill et al. 2000).

\section{Testosterone Experiment: Effects of Implantation on Male $T$ Levels, Eye Comb Size and Color, and Behavior}

Sampled at the first recapture after the implantation capture, implanted birds had significantly higher testosterone levels compared with controls (Mann-Whitney $U$-test: $N_{\text {implanted }}=8, \quad N_{\text {control }}=11, \quad Z=-2.312, \quad P=.020$; mean $_{\text {implanted }}=2.04 \mathrm{ng} \mathrm{mL}{ }^{-1}, \mathrm{SD}=.99 ; \operatorname{mean}_{\text {control }}=$ $\left.1.09 \mathrm{ng} \mathrm{L}^{-1}, \mathrm{SD}=.53\right)$. In the second capture after the implantation capture (during the mating season), we managed to recapture only eight birds, and at that capture only the implanted birds had a tendency to have higher levels of testosterone (Mann-Whitney $U$-test; $N_{\text {implanted }}=5$, $N_{\text {control }}=3, Z=-1.938, P=.053 ;$ mean $_{\text {implanted }}=1.79$ $\mathrm{ng} \mathrm{L}^{-1}, \mathrm{SD}=1.13$; mean $_{\text {control }}=.81 \mathrm{ng} \mathrm{L}^{-1}, \mathrm{SD}=.14$ ).

The growth of the eye combs between implantation capture and the first recapture was much more intensive in the implanted birds than in controls (Mann-Whitney $U$ test: $N_{\text {implanted }}=14, N_{\text {control }}=10, Z=-3.396, P=.001$; mean $_{\text {implanted }}=1.36 \mathrm{~cm}^{2}, \mathrm{SD}=.99 ;$ mean $_{\text {control }}=0.01$ $\mathrm{cm}^{2}, \mathrm{SD}=.55$; fig. 4). Redness of the eye comb did not change between implanted and control birds (inde- pendent samples $t$-test: $t=-.070, \mathrm{df}=21, P=.945$, mean $_{\text {implanted }}=-.02, \quad \mathrm{SD}=3.44 ; \quad$ mean $_{\text {control }}=.06$, $\mathrm{SD}=2.37)$. However, the eye comb size of implanted males was still smaller than that of adult males (for adults, see data in table 2).

Ten implanted birds and 11 control birds were observed lekking in the feeding sites in the year of implantation (2002). The positions of the implanted birds were closer to the lek center than the positions of the control birds (independent samples $t$-test after natural $\log$ transformation: $t=-2.186, \mathrm{df}=19, P=.042 ;$ mean $_{\text {implanted }}=$ $14.0 \mathrm{~m}$, mean $_{\text {control }}=21.3 \mathrm{~m}$ ).

\section{Testosterone Experiment: Survival between 2002 and 2005}

We followed the survival of experimental males from 2002 to 2005. All the leks within a $5-\mathrm{km}$ distance of the feeding sites were checked for male survival and mating success in 2002, 2003, 2004, and 2005. Survival differed significantly between the treatment groups (Wilcoxon Gehan statistics $=5.75, P=.017$ ), with controls having better survival than the implanted males (table 3 ).

\section{Testosterone Experiment: Morphology and Ornamentation after 10 Months}

Male traits before the implantation are presented in table 4. At the beginning of the experiment (2002), the implanted and the control males did not differ in their morphology (wing length, lyre length, weight, eye comb size) or coloration (blue chroma, eye comb redness; see table 4). The trait means in 2003 (10 months later) are presented also in table 4 . Wing length and body mass did not differ between the male groups. Lyre length was shortened by approximately $30 \%$ in implanted birds compared with controls. Furthermore, blue chroma and total reflectance of breast feathers as well as eye comb redness were lower in implanted males compared with control males. How- 
ever, UV chroma and eye comb size did not differ between the male groups, although eye comb size tended to be higher among the implanted males.

\section{Discussion}

Both principal components and calculated color indexes reveal that the short-wavelength area is important in sexual signaling in the black grouse. All the calculated chromatic color indexes and PC1 differed between male age classes, with older males having enhanced color expression. However, only blue chroma was positively significantly correlated with male mating success, and indeed it was the rather narrow range from 380 to $435 \mathrm{~nm}$ that turned out to be the most crucial wavelength area. Our testosterone implantation experiment revealed that the expression of color signals shows heightened condition dependency. This is because we observed the negative effects of our testosterone treatment on male sexual signals in the following year (after molting), but neither the wing length nor male body mass were affected. The treatment difference was the most prominent in lyre length, which was reduced even below normal population means (see table 4). Furthermore, the hormone-treated birds had reduced quality of their color signals: both the structural (breast feathers) and carotenoid-based (eye comb) coloration were negatively affected by the androgen treatment.

\section{Signal Structure}

Correlation coefficients between male mating success and the reflectance of male breast feathers across wavelengths revealed that short-wavelength reflectance (380 to $\sim 435$ $\mathrm{nm}$ ) is important in determining male mating success in this species. This was supported by the PC1 extracted with PCA after controlling for the effects of total reflectance: most of the between-male variation in reflectance spectra is in the short-wavelength area (fig. 2). A comparison of

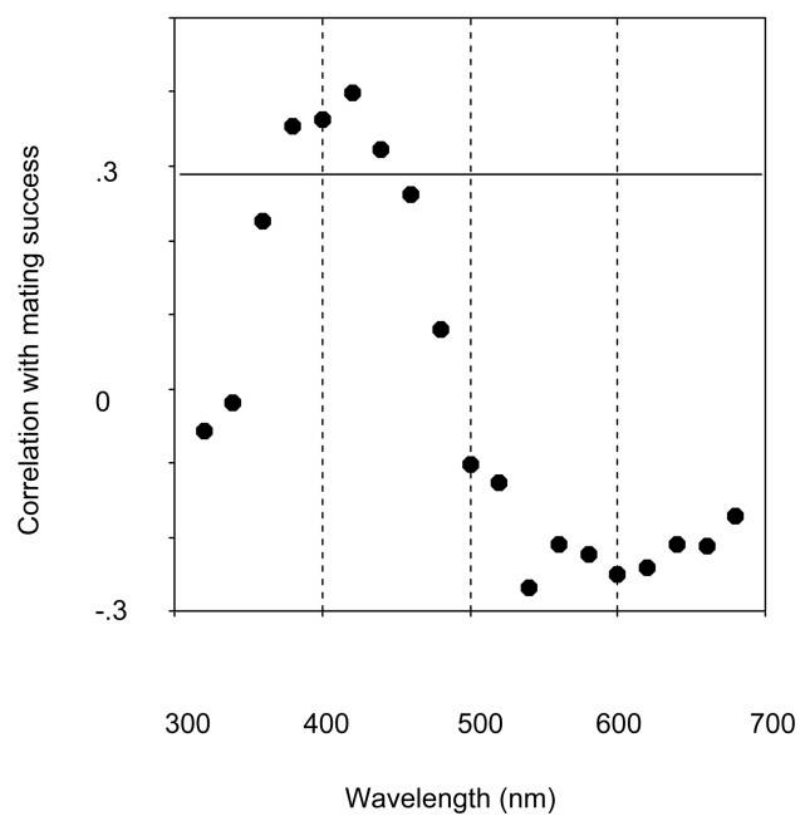

Figure 3: Spearman's rank correlation $\left(r_{\mathrm{s}}\right)$ between male mating success and the average reflectance of male breast feathers for each 20 -nm spectral interval. Horizontal line indicates the critical value for $P<.05$.

the calculated chromatic measures (UV and blue chroma) and total reflectance values with male mating success indicated that the blue chroma is significantly positively related to male mating success but not the other indexes. The short-wavelength cone sensitivity peak is at $420 \mathrm{~nm}$ in galliform species (Cuthill et al. 2000), supporting the ecological relevance of our finding that the narrow wavelength area (380-435 nm) was most important in sexual signaling.

Chromatic indexes and total reflectance, as well as PC1, are enhanced in expression in older males. This may be due to higher general quality of older individuals or simply

Table 2: Difference in color indexes, principal component (PC) scores, eye comb size and redness, and lyre length between yearling and older ( $>1$ year) males

\begin{tabular}{lcccccc}
\hline Trait & $\begin{array}{c}\text { Mean yearlings } \\
( \pm 1 \mathrm{SD})\end{array}$ & $N$ & $\begin{array}{c}\text { Mean old } \\
( \pm 1 \mathrm{SD})\end{array}$ & $N$ & $t$ & $P$ \\
\hline UV chroma (\%) & $27.17(2.4)$ & 58 & $29.22(1.9)$ & 74 & -5.291 & $<.001$ \\
Blue chroma (\%) & $24.80(1.7)$ & 58 & $26.23(1.1)$ & 74 & -5.487 & $<.001$ \\
Total reflectance & $320.09(108.1)$ & 58 & $438.07(153.1)$ & 74 & -5.184 & $<.001$ \\
PC1 & $-.554(1.1)$ & 58 & $.434(.6)$ & 74 & -6.454 & $<.001$ \\
PC2 & $-.035(1.0)$ & 58 & $.027(1.0)$ & 74 & -.355 & .783 \\
Eye comb redness & & & & & & \\
$\quad$ frequency in nm) & $589.4(2.9)$ & 55 & $592.0(2.9)$ & 44 & -5.167 & $<.001$ \\
Eye comb size $\left(\mathrm{cm}^{2}\right)$ & $4.19(1.0)$ & 55 & $6.02(1.6)$ & 44 & -6.796 & $<.001$ \\
Lyre length $(\mathrm{mm})$ & $18.96(.9)$ & 92 & $22.32(1.2)$ & 103 & -21.798 & $<.001$ \\
\hline
\end{tabular}

Note: Independent samples $t$-test used. 


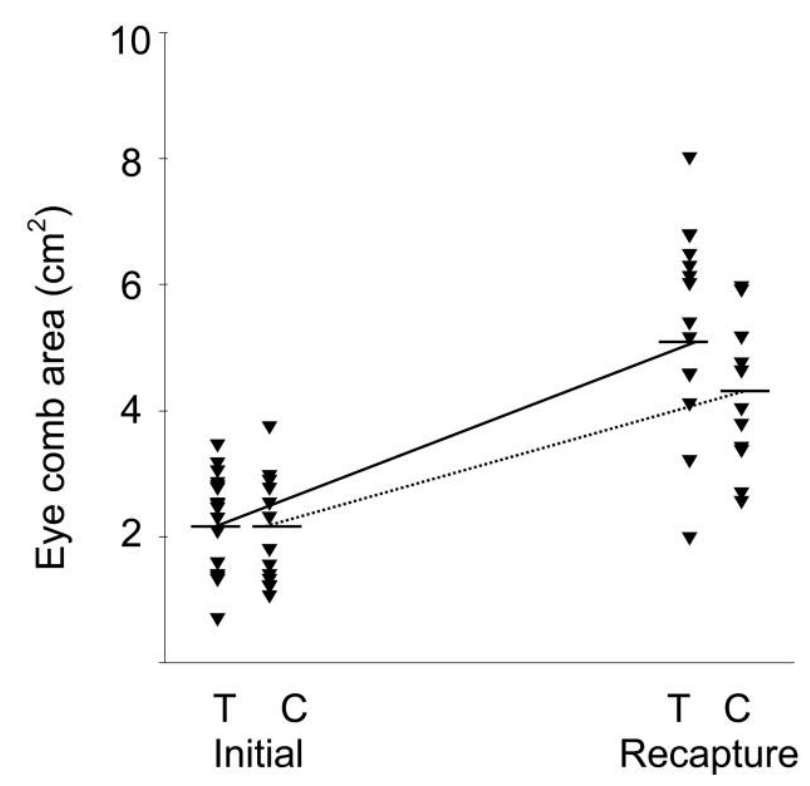

Figure 4: Change in eye comb area in implanted (solid line) and control (dashed line) males (initial and treatment response). Horizontal lines represent group means. $T=$ implanted males, $C=$ control males.

due to delayed plumage maturation in yearling individuals. However, the fact that blue chroma is related to male mating success among old males may indicate that color signals may reflect male quality in the black grouse.

\section{Testosterone Treatment, Male Signals, and Survival}

Male eye comb size increased in the testosteroneimplanted birds but not in the control birds. However, redness of the eye comb was not affected by the testosterone implantation. Red eye comb is a carotenoid-based sexual signal (Zuk et al. 1990), and in this study and others, its size has been shown to be positively related to male testosterone levels in many galliform species (Tetrao tetrix: Rintamäki et al. 2000; Lagopus lagopus scoticus: Mougeot and Redpath 2004; Gallus gallus: Zuk et al. 1995). Testosterone treatment also increased male mating effort in implanted birds: they succeeded in achieving territories closer to lek center compared with controls, a trait important for determining male mating success in black grouse (Hovi et al. 1994). Furthermore, testosterone-implanted birds had reduced survival compared with controls. However, it is possible that we have missed some survivors because of dispersal, but most of the males do not disperse farther than $5 \mathrm{~km}$ (Alatalo et al. 1991; Höglund et al. 1999). Thus, our observations are likely to reflect real survival differences between the implanted and control males. Our data suggest that our implants maintained an elevated level of testosterone during the crucial period of the study. Furthermore, during the main mating season, testosterone levels did not exceed those of active old, territorial males (data for the old males in Alatalo et al. 1996b).

The strong effect of the testosterone treatment on sexual signals in the following year, especially on lyre length and structural coloration, could arise through several pathways. In general, increased reproduction (Nordling et al. 1998) or mating effort (McKean and Nunney 2001; Kilpimaa et al. 2004) or artificially elevated testosterone levels (e.g., Peters 2000; Buchanan et al. 2003) may suppress male immune defense and/or directly cause physiological stress and damage tissues (von Schantz et al. 1999). Consequently, increased androgen levels may expose males for parasites, lead to the activation of immune defense system, and cause oxidative stress. Interestingly, there is much evidence that elevation of testosterone levels in male red grouse (Lagopus lagopus scotius) increases male parasite load (Mougeot et al. 2004, 2005a, 2005b, 2006), and they remain higher even after 1 year (Seivwright et al. 2005). They have studied the effects of testosterone on a number of parasitic nematode Trichostrongylus tenuis, but unfortunately, we were not able to study prevalence or number of macroparasites in the black grouse.

Parasites directly affect the expression of black grouse ornaments. A previous study with two separate data sets indicates that male lyre length is strongly associated with parasite levels (Höglund et al. 1992): males with longer lyre have fewer parasites. Interestingly, blue chroma is also negatively related to microfilaria blood parasite levels ( $R$. V. Alatalo, H. Siitari, J. Höglund, P. Halme, P. T. Rintamäki, and J. Kilpimaa, unpublished manuscript). The fact that structural coloration might also be sensitive to parasites is supported by a study by Hill et al. (2005): experimental infection of coccidial oocytes in wild turkeys (Meleagris gallopavo) indicates that parasites can suppress the expression of structural plumage colors. Because the lyre length was greatly shortened in the testosterone-treated group, our treatment had possibly increased the parasite loads in these birds, which in turn may have activated immune and detoxification systems, probably leading to increased levels of reactive metabolites and oxidative stress.

Table 3: Proportion of surviving males (\%) in the testosterone experiment from 2002 to 2005

\begin{tabular}{lcc}
\hline Mating season & Implanted & Control \\
\hline 2002 & 63.2 & 94.7 \\
2003 & 36.8 & 73.7 \\
2004 & 21.1 & 42.1 \\
2005 & 10.5 & 26.3 \\
\hline
\end{tabular}

Note: For statistics, see "Results" $(N=19$ in both treatments). 
Table 4: Difference in male traits before and 1 year after the testosterone implantation between experimental and control males

\begin{tabular}{|c|c|c|c|c|c|c|}
\hline Trait & $\begin{array}{l}\text { Mean implanted } \\
\qquad( \pm 1 \text { SD })\end{array}$ & $N$ & $\begin{array}{l}\text { Mean controls } \\
\qquad( \pm 1 \mathrm{SD})\end{array}$ & $N$ & $t$ & $P$ \\
\hline \multicolumn{7}{|l|}{ Before experiment (2002): } \\
\hline Wing length $(\mathrm{mm})$ & $26.3(.39)$ & 19 & $26.1(.47)$ & 19 & 1.302 & .201 \\
\hline Body mass (g) & $1,151.3(53.8)$ & 19 & $1,161.8(55.2)$ & 19 & -.592 & .557 \\
\hline Lyre length (mm) & $18.6(.64)$ & 19 & $18.73(.91)$ & 19 & -.456 & .651 \\
\hline Blue chroma $(\%)$ & $25.2(1.60)$ & 16 & $25.4(1.80)$ & 12 & -.484 & 633 \\
\hline UV chroma (\%) & $26.99(2.48)$ & 16 & $28.03(2.17)$ & 12 & -1.164 & .255 \\
\hline Total reflectance & $377.66(112.84)$ & 15 & $359.87(90.22)$ & 12 & .444 & .661 \\
\hline Eye comb redness (frequency in $\mathrm{nm}$ ) & $589.17(4.27)$ & 17 & $589.39(2.81)$ & 17 & -.180 & .850 \\
\hline Eye comb size $\left(\mathrm{cm}^{2}\right)$ & $2.29(.76)$ & 17 & $2.16(.97)$ & 15 & .430 & 671 \\
\hline \multicolumn{7}{|l|}{ After 10 months (2003): } \\
\hline Wing length $(\mathrm{mm})$ & $26.88(.39)$ & 6 & $26.98(.53)$ & 13 & -.385 & .705 \\
\hline Body mass $(\mathrm{g})$ & $1,245.00(25.88)$ & 6 & $1,266.15(41.54)$ & 13 & -.890 & .386 \\
\hline Lyre length (mm) & $15.55(.56)$ & 6 & $21.92(.89)$ & 13 & -16.00 & $<.001$ \\
\hline Blue chroma $(\%)$ & $23.87(.59)$ & 6 & $26.29(1.61)$ & 12 & -3.526 & .003 \\
\hline UV chroma (\%) & $28.94(1.17)$ & 6 & $30.25(1.99)$ & 12 & -1.478 & .159 \\
\hline Total reflectance & $212.26(64.47)$ & 6 & $464.94(268.33)$ & & -2.242 & .039 \\
\hline Eye comb redness (frequency in $\mathrm{nm}$ ) & $594.81(4.98)$ & 6 & $599.26(3.22)$ & 12 & -2.303 & .035 \\
\hline Eye comb size $\left(\mathrm{cm}^{2}\right)$ & $5.68(1.81)$ & 6 & $4.16(.79)$ & 12 & 1.967 & .097 \\
\hline
\end{tabular}

Note: Independent samples $t$-test used.

However, it is almost impossible to capture birds during the summer and early autumn when they are not in winter flocks or are in the lekking arenas but molting. In addition, we know that the mortality of the males is highest during the six consecutive months after the main mating season (Alatalo et al. 1991). The poor quality of both lyre and structural coloration in the testosterone-treated males indicates that there have possibly been developmental abnormalities during the feather development time. Only a detailed analysis of feather structure would probably give new insights for this possibility. Lyre length (sexual signal) was more affected by our treatment than the wing (not a sexual signal), and this indicates that lyre needs more time to grow, is more sensitive to testosterone, or is more sensitive to potential stress that might have been associated with our testosterone treatment.

Keratin synthesis is important in feather development and may mediate the honesty of structural color signals (Fitzpatrick 1998; Shawkey et al. 2003), as it is particularly susceptible to oxidative stress (von Schantz et al. 1999 and references therein). The recent study by Jovani and Blas (2004) emphasizes the importance of keratin synthesis in feather production. They found that in white storks ( $\mathrm{Ci}-$ conia ciconia), the occurrence of fault feather bars is more common in less important flight feathers compared with the most essential feathers, which had the least number of fault bars. Fault bars were also more common in the feathers of nestlings, which are more vulnerable to environmentally induced stress than the adults. Experimental studies of stress effects, feather nanostructure, and the ex- pression of structural colors would give some new insights to the importance of stress for the evolution of structural coloration.

\section{Acquisition and Maintenance of Black Grouse Plumage}

Elevated testosterone levels are involved in acquisition and maintenance of breeding plumage in species in which plumage is dependent on testosterone (Kimball and Ligon 1999; Peters et al. 2000). Thus, increased testosterone levels in those species should lead to high-quality (colorful) sexual ornaments. Black grouse, however, is a galliform species in which plumage is independent of testosterone (Kimball and Ligon 1999). Black grouse molt in JulyAugust, a period right after the mating time. The plumage of the black grouse is instead estrogen dependent, meaning that the presence of estrogen leads to dull, female-like plumage, while the absence of estrogen is behind the bright male plumage (Kimball and Ligon 1999). However, exceptions within Tetraonidae also exist; for example, the summer plumage of male willow ptarmigan (Lagopus lagopus lagopus) is not testosterone dependent, but the nuptial plumage (an additional plumage developed during the courtship season, between summer and winter plumages) appears to be testosterone dependent (Stokkan 1979). This does not exclude the possibility that testosterone does not affect the intrasexual variation in plumage traits. For example, in the house finch (Carpodacus mexicanus), experimentally increased testosterone levels delayed molt in both captive and wild birds. Additionally, testosterone- 
treated males molted into less colorful carotenoid-based plumage, but carotenoid supply diminished the difference (Stoehr and Hill 2001). The authors suggest that testosterone-treated males did not have enough carotenoids available at the time of delayed molt, causing the duller plumage development. Contrary to this and to our study, in a study on satin bowerbirds (Ptilonorhynchus violaceus; Collis and Borgia 1992), testosterone treatment of yearling males during the mating season induced premature development of adult characteristics, and these males developed a fully-matured deep blue adult plumage in the following year.

Although the molt takes place immediately after the breeding season, black grouse molt directly to new nuptial plumage. Thus, their plumage remains unchanged until after the next breeding season, although changes through, for example, feather wear (Örnborg et al. 2002) are possible but unstudied in black grouse. Unfortunately, we could not get direct information as to whether there was any difference in timing of molt in our implanted and control birds. In any case, at least at the time of recapturing (about 10 months after the testosterone implantation, in January-February 2003), all the birds had completely molted. The coloration of the carotenoid-based signal (red eye comb) was, however, at least marginally diminished in the treatment group compared with controls (table 4). We think that this cannot be due to lack of carotenoid availability because, at least during the molting time, the birds live in an environment with carotenoid-rich food, like berries and other plant material. However, the efficiency of carotenoid processing in the bird body might have been affected by our treatment. Furthermore, the trade-off between carotenoids needed for functioning as antioxidants or used for signal development (Blount et al. 2003) may be one plausible explanation.

\section{Conclusions}

To conclude, according to our results, plumage reflectance in short wavelengths is an important sexually selected signal in the lekking black grouse. Moreover, experimentally elevated androgen levels with artificially increased mating effort had multiple negative effects on male sexual color ornaments in the following year, after the new feathers were molted. Since the expression of both structural and carotenoid-based coloration as well as feather growth (tail length) was diminished by the treatment but the vital traits were not, our study indicates that sexual ornaments are selectively susceptible to stress and reliable indicators of a male stress resistance. Additionally, our study indicates that structural-based color ornaments are sensitive to past male condition, supporting the recent finding that structural-based color ornaments may reflect male genetic quality (Foerster et al. 2003). In general, if sexual signals are especially sensitive to past male stress and male ability to resist stress is genetically determined, female choice could drive the evolution of honest male sexual signaling.

\section{Acknowledgments}

We thank M. Halonen, L. Häsä, H. Helle, C. Lebigre, G. Ludwig, E. Mykkänen, E. Rantanen, and R. Saunanen for their invaluable help, especially in the field and the laboratory, and L. Häsä and P. Innanen for their help in measuring feathers. We are also grateful to A. Bennett, J. Komdeur, and A. Peters for invaluable comments and discussion that improved our article. The birds were captured with the permission of the Central Finland Environmental Centre (permissions KSU-2003-L-25/254 and KSU-2002L-4/254). The experiments were approved also by the Animal Care Committee of Jyväskylä University (permissions 4/8.1.2002 and 3/28.1.2003). The project was financed by the Academy of Finland (projects 20078 to H.S. and 202841 to R.V.A.).

\section{Literature Cited}

Alatalo, R. V., J. Höglund, and A. Lundberg. 1991. Lekking in black grouse: a test of male viability. Nature 352:155-156.

Alatalo, R. V., J. Höglund, A. Lundberg, and W. J. Sutherland. 1992. Evolution of black grouse leks: female preferences benefit males in larger leks. Behavioral Ecology 3:53-59.

Alatalo, R. V., T. Burke, J. Dann, O. Hanotte, J. Höglund, A. Lundberg, R. Moss, and P. T. Rintamäki. 1996a. Paternity, copulation disturbance and female choice in lekking black grouse. Animal Behaviour 52:861-873.

Alatalo, R. V., J. Höglund, A. Lundberg, P. T. Rintamäki, and B. Silverin. 1996b. Testosterone and male mating success on the black grouse leks. Proceedings of the Roval Society B: Biological Sciences 263:1697-1702.

Alonso-Alvarez, C., S. Bertrand, G. Devevey, M. Gaillard, J. Prost, B. Faivre, and G. Sorci. 2004. An experimental test of the dosedependent effect of carotenoids and immune activation on sexual signals and antioxidant activity. American Naturalist 164:651-659. Andersson, M. 1986. Evolution of condition-dependent sex ornaments and mating preferences: sexual selection based on heritable viability differences. Evolution 40:804-816.

- 1994. Sexual selection. Princeton University Press, Princeton, NJ.

Andersson, S. 1999. Morphology of UV-reflectance in a whistling thrush: implications for sexual selection. $\underline{\text { Journal of Avian Biology }}$ 30:193-204.

Andersson, S., J. Örnborg, and M. Andersson. 1998. Ultraviolet sexual dimorphism and assortative mating in blue tits. Proceedings of the Royal Society B: Biological Sciences 265:445-450.

Andersson, S., S. R. Pryke, J. Örnborg, M. J. Lawes, and M. Andersson. 2002. Multiple receivers, multiple ornaments, and a tradeoff between agonistic and epigamic signaling in a widowbird. American Naturalist 160:179-224.

Ballentine, B., and G. E. Hill. 2003. Female mate choice in relation 
to structural plumage coloration in blue grosbeaks. Condor 105: 593-598.

Bennet, A. T. D., I. C. Cuthill, and K. N. Norris. 1994. Sexual selection and the mismeasure of color. American Naturalist 144:848-860.

Bennett, A. T. D., I. C. Cuthill, J. C. Partridge, and E. J. Maier. 1996. Ultraviolet vision and mate choice in zebra finches. Nature 380: 433-435.

Bennett, A. T. D., I. C. Cuthill, J. C. Partridge, and K. Lunau. 1997. Ultraviolet plumage colors predict mate preferences in starlings. Proceedings of the National Academy of Sciences of the USA 94: $8618-8621$.

Blount, J. D., N. B. Metcalfe, T. R. Birkhead, and P. F. Surai. 2003. Carotenoid modulation of immune function and sexual attractiveness in the zebra finches. Science 300:125-127.

Buchanan, K. L., M. R. Evans, and A. R. Goldsmith. 2003. Testosterone, dominance signaling and immunosuppression in the house sparrow, Passer domesticus. Behavioural Ecology and Sociobiology 55:50-59.

Collis, K., and G. Borgia. 1992. Age-related effects of testosterone, plumage, and experience on aggression and social dominance in juvenile male satin bowerbirds (Ptilonorhynchus volaceus). Auk 109:422-434

Cotton, S., K. Fowler, and A. Pomiankowski. 2004. Do sexual ornaments demonstrate heightened condition-dependent expression as predicted by the handicap hypothesis? Proceedings of the Roval Society B: Biological Sciences 271:771-783.

Cuthill, I. C., A. T. D. Bennett, J. C. Partridge, and E. J. Maier. 1999. Plumage reflectance and the objective assessment of avian sexual dichromatism. American Naturalist 160:183-200.

Cuthill, I. C., J. C. Partridge, A. T. D. Bennett, S. C. Church, N. S. Hart, and S. Hunt. 2000. Ultraviolet vision in birds. Advances in the Study of Behaviour 29:159-214.

Endler, J. A. 1990. On the measurement and classification of colour in studies of animal colour patterns. Biological Journal of the Linnean Society 41:315-352.

Endler, J. A., and M. Théry. 1996. Interacting effects of lek placement, display behaviour, ambient light, and color patterns in three Neotropical forest-dwelling birds. American Naturalist 148:421-452.

Fitzpatrick, S. 1998. Colour schemes for birds: structural coloration and signals of quality in feathers. Annales Zoologici Fennici 35: $67-77$.

Foerster, K., K. Delhey, J. T. Lifjeld, and B. Kempenaers. 2003. Females increase offspring heterozygosity and fitness through extra-pair matings. Nature 425:714-717.

Folstad, I., and A. J. Karter. 1992. Parasites, bright males and the immunocompetence handicap. American Naturalist 139:603-622.

Fox, L. D. 1976. Animal biochromes and structural colors. University of California Press, Berkeley.

Grafen, A. 1990. Sexual selection unhandicapped by the Fisher process. Journal of Theoretical Biology 144:473-516.

Griffith, S. C., J. Örnborg, A. F. Russell, S. Andersson, and B. C. Sheldon. 2003. Correlations between ultraviolet coloration, overwinter survival and offspring sex ratio in the blue tit. Journal of Evolutionary Biology 16:1045-1054.

Hamilton, W. D., and M. Zuk. 1982. Heritable true fitness and bright plumage in birds: a role for parasites? Science 218:384-387.

Hasselquist, D., S. Bensch, and T. von Schantz. 1996. Correlation between male song repertoire, extra-pair paternity and offspring survival in the great reed warbler. Nature 381:229-232.
Hill, G. E. 1991. Plumage coloration is a sexually selected indicator of male quality. Nature 350:337-339.

. 1999. Mate choice, mate quality and carotenoid-based plumage colouration. Proceedings of the International Ornithological Congress 22:1654-1668.

Hill, G. E., S. M. Doucet, and R. Buchholz. 2005. The effect of coccidial infection on iridescent plumage coloration in wild turkeys. Animal Behaviour 69:387-394.

Höglund, J., and R. V. Alatalo. 1995. Leks. Princeton University Press, Princeton, NJ.

Höglund, J., R. V. Alatalo, and A. Lundberg. 1992. The effects of parasites on male ornaments and female choice in the lekking black grouse (Tetrao tetrix). Behavioural Ecology and Sociobiology 30:71-76

Höglund, J., R. V. Alatalo, A. Lundberg, P. T. Rintamäki, and J. Lindell. 1999. Evolution of black grouse leks: kin selection revealed by microsatellite markers. Proceedings of the Roval Society B: Biological Sciences 266:813-816.

Hovi, M., R. V. Alatalo, J. Höglund, A. Lundberg, and P. T. Rintamäki. 1994. Lek centre attracts black grouse females. Proceedings of the Royal Society B: Biological Sciences 258:303-305.

Hunt, S., A. T. D. Bennett, I. C. Cuthill, and R. Griffiths. 1998. Blue tits are ultraviolet tits. Proceedings of the Royal Society B: Biological Sciences 265:451-455.

Hunt, S., I. C. Cuthill, A. T. D. Bennett, and R. Griffiths. 1999. Preferences for ultraviolet partners in the blue tit. Animal Behaviour 58:809-815.

Iwasa, Y., and A. Pomiankowski. 1994. The evolution of mate preferences for multiple handicaps. Evolution 48:853-867.

1999. Good parent and good genes of handicap evolution. Journal of Theoretical Biology 200:97-109.

Johnsen, A., K. Delhey, S. Andersson, and B. Kempenaers. 2003. Plumage colour in nestling blue tits: sexual dichromatism, condition dependence and genetic effects. Proceedings of the Roval Society B: Biological Sciences 270:1263-1270.

Jovani, R., and J. Blas. 2004. Adaptive allocation of stress-induced deformities on bird feathers. Journal of Evolutionary Biology 17: 294-301.

Keyser, A. J., and G. E. Hill. 1999. Condition-dependent variation in the blue-ultraviolet colouration of a structurally based plumage ornament. Proceedings of the Roval Society B: Biological Sciences 266:771-777.

2000. Structurally based plumage coloration is an honest signal of quality in male blue grosbeaks. Behavioral Ecology 11: 202-209.

Kilpimaa, J., R. V. Alatalo, and H. Siitari. 2004. Trade-off between sexual advertisement and immune function in the pied flycatcher (Ficedula hypoleuca). Proceedings of the Roval Society B: Biological Sciences 271:245-250.

Kimball, R. T., and J. D. Ligon. 1999. Evolution of avian plumage dichromatism from a proximate perspective. American Naturalist 154:182-193.

McGraw, K. J., E. A. Mackillop, J. Dale, and M. E. Hauber. 2002. Different colors reveal different information: how nutritional stress affects the expression of melanin- and structurally based ornamental plumage. Journal of Experimental Biology 205:3747-3755.

McKean, K. A., and L. Nunney. 2001. Increased sexual activity reduces male immune function in Drosophila melanogaster. Proceedings of the National Academy of Sciences of the USA 98:7904-7909.

Møller, A. P., and R. V. Alatalo. 1999. Good-genes effects in sexual 
selection. Proceedings of the Roval Society B: Biological Sciences 266:85-91.

Mougeot, F., and S. M. Redpath. 2004. Sexual ornamentation relates to immune function in male red grouse Lagopus lagopus scotius. Journal of Avian Biology 35:425-433.

Mougeot, F., J. Irvine, L. J. Seivwright, S. Redpath, and S. B. Piertney. 2004. Testosterone, immunocompetence and honest sexual signalling in male red grouse. Behavioral Ecology 15:630-637.

Mougeot, F., S. Redpath, S. B. Piertney, and P. J. Hudson. $2005 a$. Separating behavioral and physiological mechanisms in testosterone-mediated trade-offs. American Naturalist 166:158-168.

Mougeot, F., A. Dawson, S. Redpath, and F. Leckie. 2005b. Testosterone and autumn territorial behaviour in male red grouse $\mathrm{La}$ gopus lagopus scoticus. Hormones and Behaviour 47:576-584.

Mougeot, F., S. Redpath, and S. B. Piertney. 2006. Elevated spring testosterone increases parasite intensity in male red grouse. $\underline{\mathrm{Be}-}$ havioral Ecology 17:117-125.

Nordling, D., M. Andersson, S. Zohari, and L. Gustafsson. 1998. Reproductive effort reduces specific immune response and parasite resistance. Proceedings of the Roval Society B: Biological Sciences 265:1291-1298.

Örnborg, J., S. Andersson, S. C. Griffith, and B. C. Sheldon. 2002. Seasonal changes in a ultraviolet structural colour signal blue tits, Parus caeruleus. Biological Journal of the Linnean Society 76:237245.

Osorio, D., and M. Vorobyev. 2005. Photoreceptor spectral sensitivities in terrestrial animals: adaptations for luminance and colour vision. Proceedings of the Royal Society B: Biological Sciences 272: $1745-1752$.

Palokangas, P., E. Korpimäki, H. Hakkarainen, E. Huhta, P. Tolonen, and R. V. Alatalo. 1994. Female kestrels gain reproductive success by choosing brightly ornamented males. Animal Behaviour 47: 443-448.

Parkinson, T. J., and B. K. Follett. 1995. Thyroidectomy abolishes seasonal testicular cycles of Soay rams. Proceedings of the Royal Society B: Biological Sciences 259:1-6.

Pearn, S., A. T. D. Bennett, and I. Cuthill. 2001. Ultraviolet vision, fluorescence and mate choice in a parrot, budgerigar Melopsittacus undulates. Proceedings of the Roval Societv B: Biological Sciences 268:2273-2279.

Peters, A. 2000. Testosterone treatment is immunosuppressive in superb fairy-wrens, yet free-living males with high testosterone are more immunocompetent. Proceedings of the Royal Society B: Biological Sciences 267:883-889.

Peters, A., L. B. Astheimer, R. J. Boland, and A. Cockburn. 2000. Testosterone is involved in acquisition and maintenance of sexually selected male plumage in superb fairy-wrens, Malurus cyaneus. Behavioral Ecology and Sociobiology 47:438-445.

Petrie, M. 1994. Improved growth and survival of offspring of peacocks with more elaborate trains. Nature 371:598-599.

Pomiankowski, A. 1987. Sexual selection: the handicap principle does work-sometimes. Proceedings of the Roval Society B: Biological Sciences 231:123-145.

Prough, R. A., M. W. Linder, J. A. Pinaire, G.-H. Xiao, and K. C. Falkner. 1996. Hormonal regulation of hepatitic enzymes involved in foreign compound metabolism. FASEB Journal 10:1369-1377.

Pryke, S. R., and S. Andersson. 2003. Carotenoid-based status sig- nalling in red-shouldered widowbirds (Euplectes axillaries): epaulet size and redness affect captive and territorial competition. Behavioral Ecology and Sociobiology 53:393-401.

Pryke, S. R., S. Andersson, M. J. Lawes, and S. E. Piper. 2002. Carotenoid status signaling in captive and wild red-collard widowbirds: independent effects of badge size and color. Behavioral Ecology 13:622-631.

Råberg, L., M. Grahn, D. Hasselquist, and E. Svensson. 1998. On the adaptive significance of stress-induced immunosuppression. Proceedings of the Roval Societv B: Biological Sciences 265:1637-1641.

Rintamäki, P. T., J. Höglund, E. Karvonen, R. V. Alatalo, N. Björklund, A. Lundberg, O. Rätti, and J. Vouti. 2000. Combs and sexual selection in black grouse (Tetrao tetrix). Behavioral Ecology 11: 465-471.

Seivwright, L. J., S. Redpath, F. Mougeot, F. Leckie, and P. J. Hudson. 2005. Interactions between intrinsic and extrinsic mechanism in a cyclic species: testosterone increases parasite infection in red grouse. Proceedings of the Royal Society B: Biological Sciences 272:2299-2304.

Senar, J. C. 1998. Plumage colouration as a signal of social status. Proceedings of the International Ornithological Congress 22:16691686.

Shawkey, M. D., A. M. Estes, L. M. Siefferman, and G. E. Hill. 2003. Nanostructure predicts intraspecific variation in ultraviolet-blue plumage colour. Proceedings of the Royal Society B: Biological Sciences 270:1455-1460.

Sheldon, B. C., J. Merilä, A. Qvarnström, L. Gustafsson, and H. Ellegren. 1997. Paternal genetic contribution to offspring condition predicted by size of male secondary sexual character. Proceedings of the Royal Society B: Biological Sciences 264:297-302.

Sheldon, B. C., S. Andersson, S. C. Griffith, J. Örnborg, and J. Sendecka. 1999. Ultraviolet colour variation influences blue tit sex ratios. Nature 402:874-877.

Siitari, H., and E. Huhta. 2002. Individual color variation and male quality in pied flycatchers (Ficedula hypoleuca): a role of ultraviolet. Behavioral Ecology 13:737-741.

Siitari, H., J. Honkavaara, E. Huhta, and J. Viitala. 2002. Ultraviolet reflection and female mate choice in the pied flycatcher (Ficedula hypoleuca). Animal Behaviour 63:97-102.

Stoehr, A. M., and G. E. Hill. 2001. The effects of elevated testosterone levels on plumage hue in male house finches. Iournal of Avian Biology 32:153-158.

Stokkan, K.-A. 1979. Testosterone and daylength-dependent development of comb size and breeding plumage of male willow ptarmigan (Lagopus lagopus lagopus). Auk 96:106-115.

von Schantz, T., S. Bensch, M. Grahn, D. Hasselquist, and H. Wittzel. 1999. Good genes, oxidative stress and condition-dependent sexual signals. Proceedings of the Roval Society B: Biological Sciences 266:1-12.

Zuk, M., R. Thornhill, J. D. Ligon, K. Johnson, S. Austad, S. H. Ligon, N. W. Thornhill, and C. Costin. 1990. The role of male ornaments and courtship behavior in female mate choice of red jungle fowl. American Naturalist 136:459-473.

Zuk, M., T. S. Johnsen, and T. Maclarty. 1995. Endocrine-immune interactions, ornaments and mate choice in red jungle fowl. Proceedings of the Roval Societv B: Biological Sciences 260:205-210.

Symposium Editor: Marc Théry 